\title{
The Effects of Azathioprine (Imuran) on Purine Synthesis in Clinical Disorders of Purine Metabolism*
}

\author{
William N. Kelley, Frederick M. Rosenbloom, and J. Edwin Seegmiller \\ (From the Section on Human Biochemical Genetics, National Institute of Arthritis and Meta- \\ bolic Diseases, National Institutes of Health, Bethesda, Maryland)
}

\begin{abstract}
Azathioprine, a purine analogue, significantly suppressed the purine synthesis de novo of two gouty patients manifesting overproduction of uric acid, as well as three of four gouty patients who showed normal uric acid production. This suppression is taken as evidence that phosphoribosylpyrophosphate amidotransferase, the rate-controlling step in purine synthesis de novo, has a normal sensitivity to feedback inhibitors in the patients who responded to the drug.

Two children afflicted with the familial disorder of hyperuricemia, choreoathetosis, and self-mutilation described by Lesch and Nyhan showed no reduction in the activity of the biosynthetic pathway in response to azathioprine. This inability to respond to azathioprine can be directly related to the absence in these patients of the enzyme hypoxanthine-guanine phosphoribosyltransferase which is required for conversion of the drug or its metabolites to the biochemically active ribonucleotide form.
\end{abstract}

\section{Introduction}

Numerous studies in the past decade have demonstrated that a significant proportion of gouty patients have a metabolic defect characterized by synthesis of abnormally large quantities of uric acid (1-4). The underlying biochemical mechanism responsible for the overproduction of uric acid has not yet been defined, but several hypotheses have been proposed. These are based on biochemical evidence that the rate of purine biosynthesis in bacterial (5), avian (6), and mammalian (7) cells is normally under feedback control in which purine ribonucleotides inhibit the activity of phosphoribosylpyrophosphate amidotransferase, the enzyme that catalyzes the first unique reaction of purine biosynthesis. An increased rate of purine biosynthesis could result from a loss of the sensitivity of this enzyme to feedback inhibitors, from a diminished concentration of the normal

* Submitted for publication 27 March 1967; accepted 7 June 1967.

$\ddagger$ Address requests for reprints to Dr. J. Edwin Seegmiller Section on Human Biochemical Genetics, 10-8D19, National Institute of Arthritis and Metabolic Diseases, Bethesda, Md. 20014. end products that function as feedback inhibitors, or from an increase in concentration of one of the substrates available for this rate-limiting reaction (8).

Sorensen found that the excessive purine synthesis of three gouty patients was inhibited by administration of the purine analogue azathioprine (Imuran) $(9,10)$, as shown by a decrease in the uric acid content of both plasma and urine. A decrease in the extent of incorporation of glycine${ }^{1-14} \mathrm{C}$ into urinary uric acid to values in the range found in control subjects provided additional evidence that azathioprine was suppressing synthesis of purines de novo. On the other hand, two normal subjects and one gout patient who produced normal quantities of uric acid showed no significant change in the uric acid content of plasma or urine in response to azathioprine treatment. These results led Sorensen to suggest that azathioprine treatment produces a unique effect on those gouty patients who show overproduction of uric acid. The basis of this selective action of azathioprine is not known, but since azathioprine or its metabolites may act as pseudofeedback inhibitors of purine biosynthesis de novo, these find- 
ings imply that the regulation of purine synthesis may differ in these two varieties of gout.

In our study the effects of azathioprine on purine synthesis has been determined in three groups of patients in the hope of further characterizing clinical abnormalities of purine synthesis. The patients studied included gouty patients who synthesize excessive quantities of uric acid, gouty patients who produce normal quantities of uric acid, and children with the familial syndrome recently described by Lesch and Nyhan (11) in whom excessive purine synthesis is associated with choreoathetosis, spasticity, mental retardation, and compulsive biting with mutilation of their fingers and lips.

\section{Methods}

Purine biosynthesis was assessed in three ways: (a) by determining the incorporation of isotopically labeled glycine into urinary uric acid, $(b)$ by measuring the body pool size and turnover of uric acid using uric acid labeled with a different isotope, and $(c)$ by analyzing for the concentration of uric acid contained in serum and the total quantity in the daily urine.

Glycine $-{ }^{16} \mathrm{~N}$ was synthesized as previously described $(12,13)$ with an isotope abundance after the addition of carrier of 62.0 at.\% excess. Uric acid-2 ${ }^{14} \mathrm{C}, 12.1 \mu \mathrm{c} /$ mmole was synthesized, characterized and prepared for injection as described previously (4). Glycine- $1-{ }^{14} \mathrm{C}$ was obtained from Tracerlab (Laboratory for Electronics, Inc., Waltham, Mass.) with a specific activity of 1.33 and 2.44 $\mathrm{mc} / \mathrm{mmole}$, and from Nuclear-Chicago with a specific activity of $18.75 \mathrm{mc} / \mathrm{mmole}$. Uric acid-1,3- ${ }^{15} \mathrm{~N}$ was obtained from Isomet Corporation (Palisade Park, N. J.) with a total enrichment of 46.93 at.\% excess ${ }^{15} \mathrm{~N}$. It was prepared as the lithium salt in a $5 \%$ dextrose solution and sterilized by Millipore filtration for injection. In each patient the same lot of isotopically labeled material was used in the control study and in the study conducted during treatment with azathioprine. The isolation of uric acid from urine and the determination of ${ }^{15} \mathrm{~N}$ and ${ }^{14} \mathrm{C}$ content were performed as previously described (14). Calculations of the body urate pool and turnover were identical with those of Benedict et al. (15). Azathioprine- $8-{ }^{14} \mathrm{C}$, with a specific activity of $0.03 \mathrm{mc} / \mathrm{mmole}$, was synthesized by Miss Gertrude Elion and provided through the courtesy of Burroughs-Wellcome \& Co. (Tuckahoe, N. Y.). The uric acid content of serum and urine was determined by a specific enzymatic procedure (16). Urinary and plasma oxypurines were determined by enzymatic conversion to uric acid (17). The creatinine content of all urine collected was determined by the method of Taussky (18).

The patients were admitted to the hospital and maintained on a diet essentially free of purines which contained $2600 \mathrm{cal}, 70 \mathrm{~g}$ of protein, $350 \mathrm{~g}$ of carbohydrate, and $100 \mathrm{~g}$ of fat for at least 4 days before studies were initiated and throughout the study period. All urine was collected at room temperature, using $3 \mathrm{ml}$ of toluene as preservative for each $24-\mathrm{hr}$ collection. All gouty subjects had been hyperuricemic while on their regular diet and had experienced typical episodes of acute gouty arthritis in the past. They ranged in age from 27 to $67 \mathrm{yr}$. Subjects D. F. and F. H. had the typical features of hyperuricemia, compulsive biting with self-mutilation, choreoathetosis, spasticity, and mental deficiency described initially by Lesch and Nyhan (11). A clinical description of the patients appears elsewhere [F. H. (19), and D. F.].1 They were both $14 \mathrm{yr}$ of age at the time of the studies. Neither had a history suggestive of gouty arthritis. In none of the subjects were tophi visible, although several of the gouty patients showed radiographic changes suggestive of tophaceous deposits. Two gouty subjects, J. F. and R. L., had moderate impairment of renal function with creatinine clearances of 37 and 51 $\mathrm{ml} / \mathrm{min}$ per $1.73 \mathrm{~m}^{2}$, respectively, as did both patients D. F. and F. H. with the Lesch-Nyhan syndrome, as shown by creatinine clearances of 66 and $68 \mathrm{ml} / \mathrm{min}$, respectively, corrected to $1.73 \mathrm{~m}^{2}$. All the gouty subjects had been treated with uricosuric drugs at some time in the past, and two patients, J. F. and B. P., had been treated with allopurinol before the equilibration period. Neither subject with the Lesch-Nyhan syndrome had received uricosuric drugs, but patient D. F. had been given allopurinol. Uricosuric drugs and allopurinol were discontinued at least 5 days before the administration of labeled compounds. Patient B. P. was maintained on colchicine $1.2 \mathrm{mg} /$ day during the period of the study. Patients B. $P$. and $F$. $H$. were receiving oral sodium bicarbonate at a dose of 9.6 and $2.4 \mathrm{~g} /$ day, respectively; patient D. F. was receiving phenobarbital $45 \mathrm{mg} /$ day, and diazapam (Valium) $15 \mathrm{mg} /$ day, during both the control and study periods.

Azathioprine (Imuran), [6-(1'-methyl-4-nitro-5'-imidazolyl) thiopurine], provided by Burroughs-Wellcome \& Co., was administered to all subjects as a single daily dose of $4 \mathrm{mg} / \mathrm{kg}$ beginning 4 days before the administration of the isotopes. Subjects E. H., R. L., and F. H. received the drug for a total of 6 days, whereas patients J. F., B. P., and D. F. received it for 12,10 , and 12 days, respectively.

The control study for patients J. F., B. P., D. F., and F. H. was conducted just before the study using azathioprine, but that for patient R. McJ. was carried out 4 months after azathioprine administration. Each of these patients received $5 \mu \mathrm{c}$ of glycine- $1-{ }^{14} \mathrm{C}$ orally with their breakfast milk and $20 \mathrm{mg}$ of uric acid $-1,3-{ }^{15} \mathrm{~N}$ as the lithium salt, intravenously. The data obtained with azathioprine administration to subjects E. H., R. L., and T. B. were compared to control studies of these patients previously reported from this laboratory (4). The former two patients, E. H. and R. L., received $100 \mathrm{mg} / \mathrm{kg}$ of glycine- ${ }^{15} \mathrm{~N}$ orally with their breakfast milk and 0.5

${ }^{1}$ Smith, M. G., J. H. Bland, W. N. Kelley, and J. E. Seegmiller. In preparation. 
TABLE I

Effect of azathioprine on serum and urinary uric acid

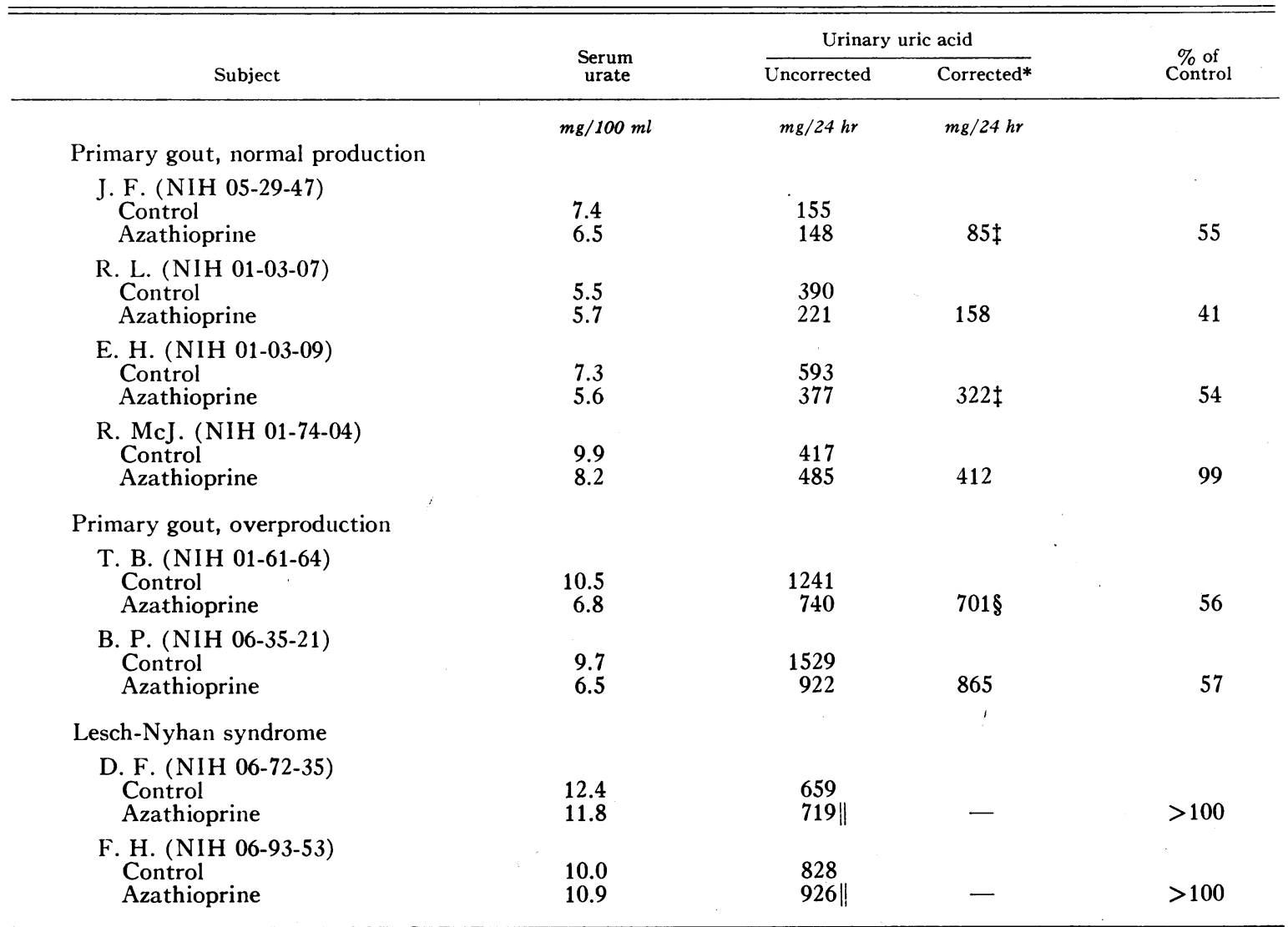

* Corrected for the conversion of azathioprine to uric acid (Table III) as described in Methods.

$\ddagger$ Correction based on values obtained in patient $R$. $L$.

\& Correction based on values obtained in patient $\mathrm{B}$. $\mathrm{P}$.

II For corrected values to be $<100 \%$ of control values in patients D. F. and F. H. $>75$ and $98 \%$ conversion of the administered azathioprine to urinary uric acid would be required.

$\mu \mathrm{c}$ of uric acid-2 ${ }^{14} \mathrm{C}$ intravenously as the lithium salt. The latter subject, T. B., received $2.5 \mu \mathrm{c}$ of glycine-1 $-{ }^{14} \mathrm{C}$ orally and uric acid-1,3-15 $N$ intravenously, as described above, and results obtained were corrected to a standard dose of $5.0 \mu$ c. Patients R. L., R. McJ., and B. P. were given $10.8 \mu \mathrm{c}$ of azathioprine- $8-{ }^{14} \mathrm{C}$ orally with breakfast and the recovery of ${ }^{14} \mathrm{C}$ in urinary uric acid was followed for the next 7 days. The dose of isotopic azathioprine administered had no discernable effect on serum and urinary uric acid content.

Studies of the metabolic fate of 6 -mercaptopurine- $6-{ }^{-35} \mathrm{~S}$ in man (20) have shown recovery of up to $20 \%$ of the administered ${ }^{35} \mathrm{~S}$ in urinary sulfate. The purine formed as a result of sulfur removal should be readily converted to uric acid and excreted in the urine. Evidence of such a conversion was obtained by administering azathioprine${ }^{8-14} \mathrm{C}^{2}$ the nitromethylimidazolyl derivative of 6-mercap-

${ }^{2}$ Elion, G. B., W. N. Kelley, and J. E. Seegmiller. In preparation. topurine to three patients, R. L., B. P., and R. McJ. and after the recovery of ${ }^{14} \mathrm{C}$ in urinary uric acid (Table III). This recovery value was then used to calculate the amount of uric acid formed from the unlabeled azathioprine and to correct the urinary uric acid for this contribution. In the three gouty subjects not studied with azathioprine- $8-{ }^{14} \mathrm{C}$, the appropriate corrections for conversion of azathioprine to uric acid were made by assuming that patients with apparently similar derangements in purine metabolism would show similar conversions of azathioprine to uric acid (Table I). The uncorrected values were used in all isotope calculations. Although the uric acid contributed from azathioprine would tend to lower the specific activity of urinary uric acid it would not alter the cumulative recovery of isotope from administered glycine into the uric acid of the urine.

In those cases where the control study was followed by a repeat administration of isotope during azathioprine treatment, it was necessary during the second part of the study to correct for the residual isotopic contribu- 
tion resulting from the first portion of the study. This was accomplished graphically by extrapolating the curve which related the specific activity of the uric acid as a function of time in the first study through the second study period, and subtracting this value as a background to obtain the corrected values for isotope enrichment (Fig. 3).

\section{Results}

As depicted in Table I, the mean excretion of uric acid during 7 days of study on a purine-free diet during the control period ranged from 155 to $593 \mathrm{mg} / 24 \mathrm{hr}$ in the gouty patients classed as normal producers of uric acid, and was 1241 and 1529 $\mathrm{mg} / 24 \mathrm{hr}$ in the two gouty patients who synthesized excessive quantities of uric acid. The administration of azathioprine reduced the mean daily excretion of uric acid (after correction for the contribution of the drug as described in Methods) to values of $85-412 \mathrm{mg} / 24 \mathrm{hr}$ in the former group and 701 and $865 \mathrm{mg} / 24 \mathrm{hr}$ in the latter group. The magnitude of the per cent decrease in urinary uric acid observed in gouty patients with overproduction of uric acid was within the range found in gouty patients who had a normal production of uric acid, with the striking exception of patient $\mathrm{R}$. McJ. in whom a value of $99 \%$ was obtained. Although the serum urate tended to fall slightly $(0.9-1.7 \mathrm{mg} / 100 \mathrm{ml})$ from the control period to the end of the treatment period in three of the four normal producers, the effect was much more striking in the overproducers studied, with decreases of 3.7 and $3.2 \mathrm{mg} / 100 \mathrm{ml}$. As shown in Fig. 1, patient B. P. showed a decrease in urinary excretion of uric acid within $24 \mathrm{hr}$ of starting the

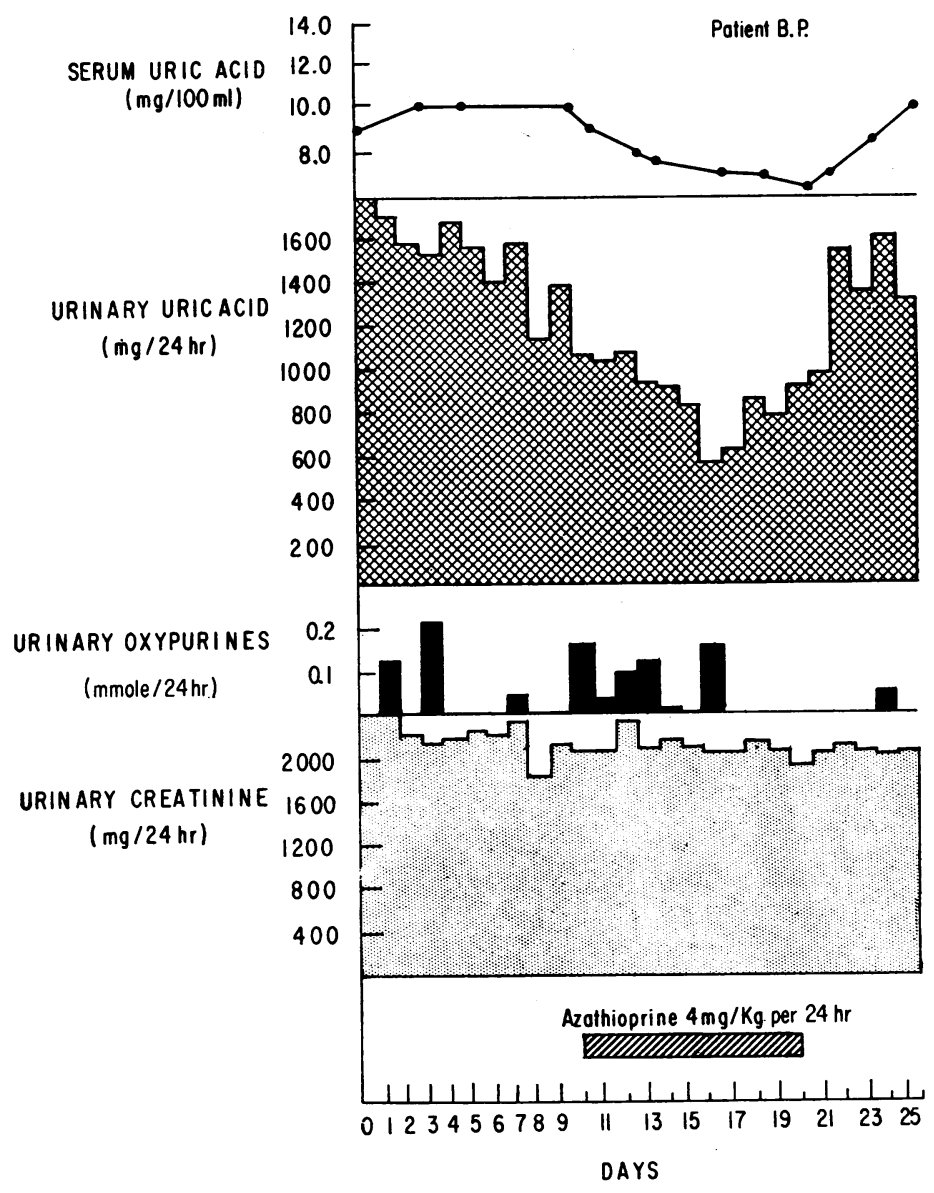

Fig. 1. The efFect OF AZATHIOPRINe treatment ON THE SERUM URATE AND 24-HR URINARY URIC ACID EXCRETION OF A GOUTY PATIENT WHO PRODUCES EXCESSIVE QUANTITIES OF URIC ACID (B. P.). 


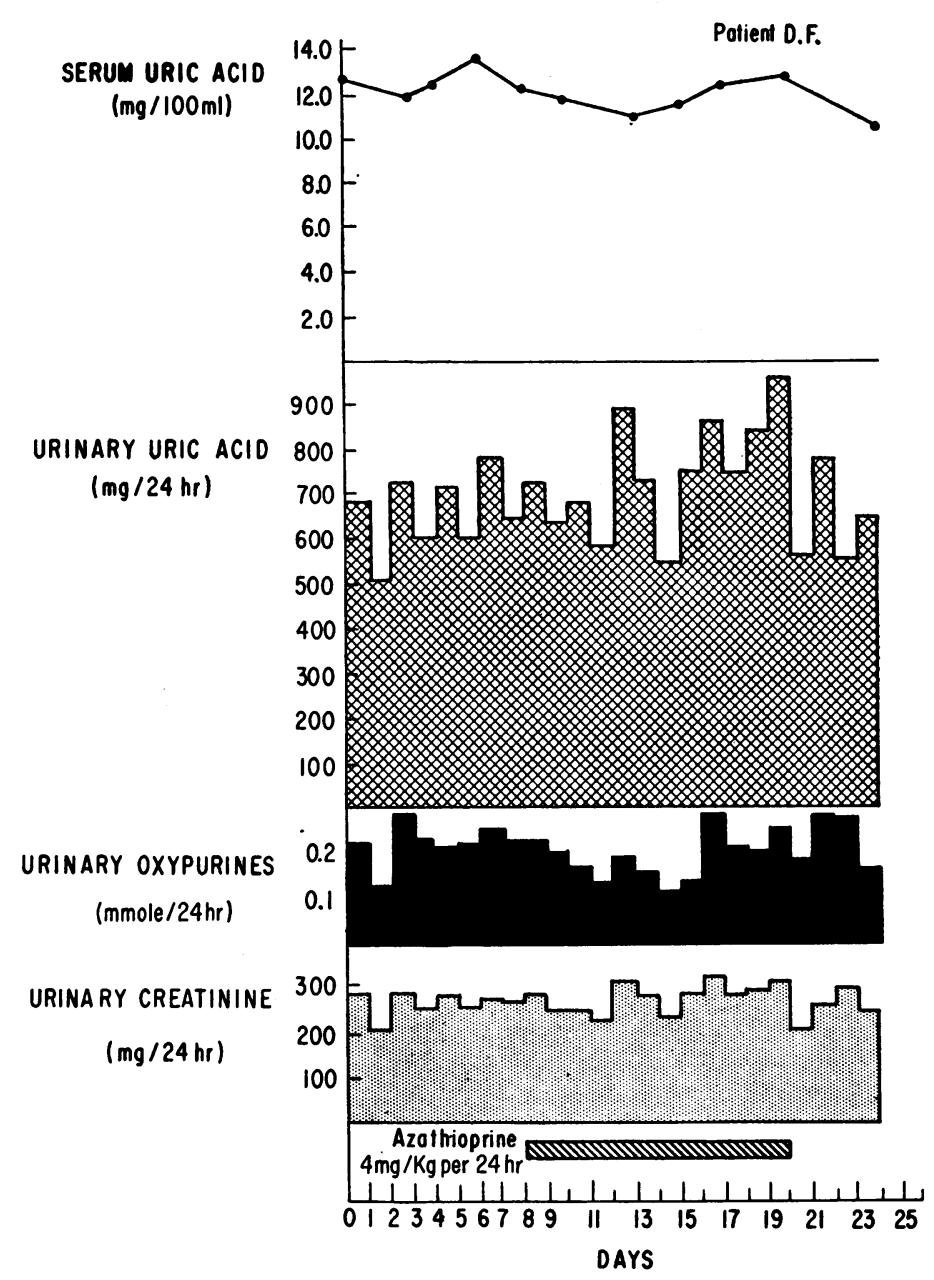

Fig. 2. THE EFFECT OF AZATHIOPRINE TREATMENT ON THE SERUM URATE AND 24-HR URINARY URIC ACID EXCRETION OF A PATIENT WITH THE LESCH-NYHAN SYNDROME (D. F.).

drug, and recovery seemed to be complete $24 \mathrm{hr}$ after stopping the drug. We found no evidence of an "overshoot" during the postazathioprine period.

The data expressed in Table I demonstrate that the basal uric acid excretion in the two patients studied with the Lesch-Nyhan syndrome is very high, as previously reported (11). The mean control values of 659 and $828 \mathrm{mg} / 24 \mathrm{hr}$ are even more striking when expressed on a weight basis. Whereas the two gouty overproducers studied excreted 12.8 and $13.9 \mathrm{mg} / \mathrm{kg}$ per $24 \mathrm{hr}$, patients D. F. and F. H. excreted 36.0 and $36.6 \mathrm{mg} / \mathrm{kg}$ per $24 \mathrm{hr}$, respectively. In contrast to the findings in gouty patients, administration of azathioprine resulted in no decrease in uric acid excretion in these two patients. In fact, both of them showed a modest increase in excretion to values that could be corrected to the control levels only by assuming 75 and $98 \%$ conversion, respectively, of the administered azathioprine to urinary uric acid. The serum urate values did not change significantly, showing a slight decrease in D. F., 0.6 $\mathrm{mg} / 100 \mathrm{ml}$, and a slight increase in F. H., $0.9 \mathrm{mg} /$ $100 \mathrm{ml}$. Fig. 2 shows the daily excretion of uric acid and the serum urate values of patient D. F. before and during azathioprine treatment and is compared to data (uncorrected) obtained under the same conditions in a gouty patient B. P. who produces excessive quantities of uric acid (Fig. 1).

As noted in Fig. 3, azathioprine administration produced a marked reduction in the specific activity and a distinct alteration in the pattern of 

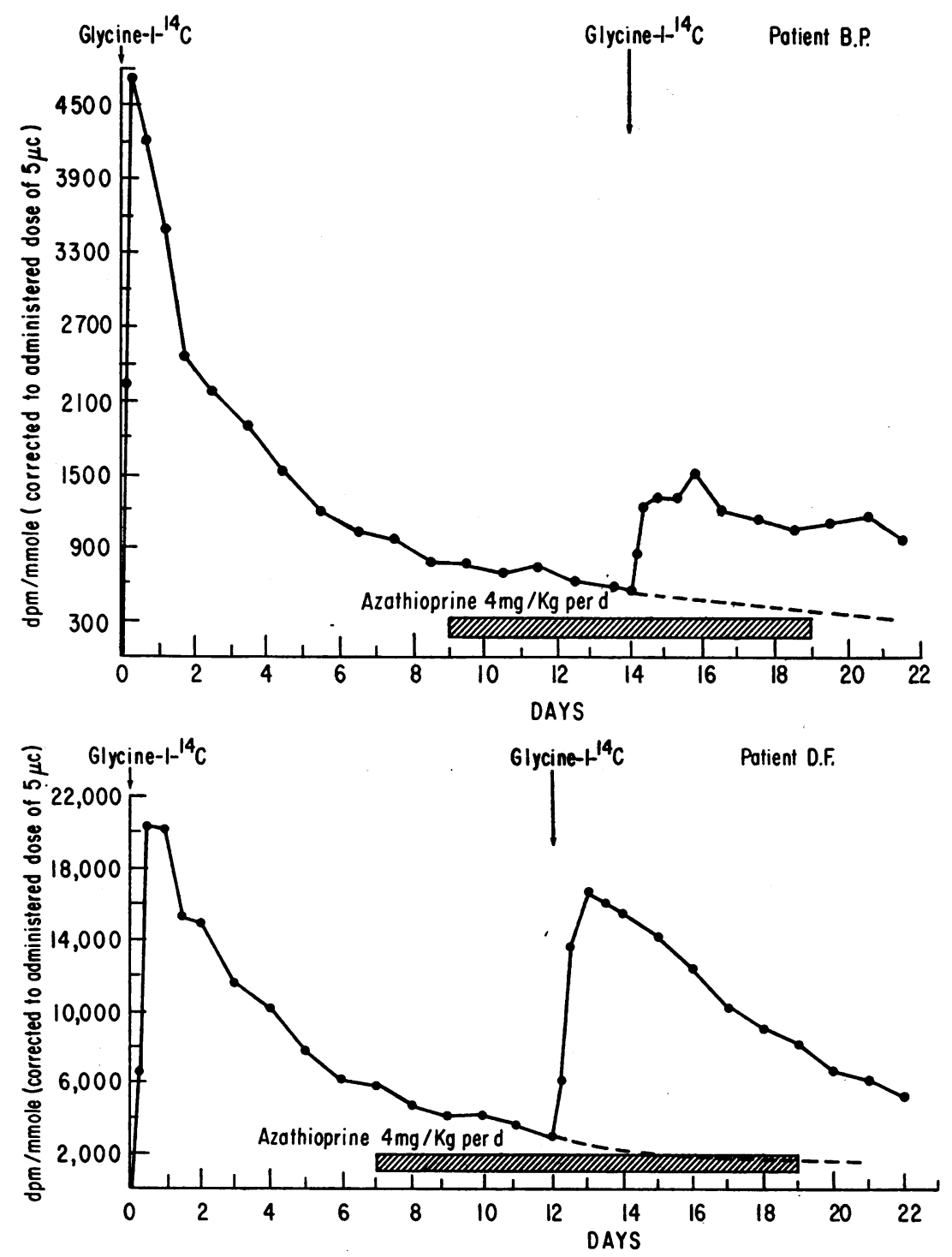

Fig. 3. The effect of AZAThioprine on the inCorporation of GLYCINe-1 $-{ }^{14} \mathrm{C}$ INTO URINARY URIC ACID IN A GOUTY PATIENT WHO OVERPRODUCES URIC ACID (B. P.) and in a patient with the Lesch-Nyhan syndrome (D. F.). Day, d.

labeling of urinary uric acid by glycine $-1-{ }^{14} \mathrm{C}$ in patient B. P. A similar diminution of specific activity in response to azathioprine was found in five of the six gouty patients studied, with patient $\mathrm{R}$. McJ. again representing the notable exception. The cumulative excretion of isotope in urinary uric acid over a 7 day period expressed as percentage of administered isotopic glycine was quite different in the two groups of gouty patients during the control periods, as shown in Table II. In the gouty normal producers of uric acid, 0.08-
$0.35 \%$ of the isotope was excreted in uric acid over a 7 day period. In the two gouty overproducers of uric acid, 1.11 and $1.24 \%$ of the administered isotope was so recovered. Azathioprine administration reduced the isotope recovered in uric acid to $0.03-0.07 \%$ in the former group, excluding patient R. McJ., and to $0.22-0.28 \%$ in the latter group, thus demonstrating a comparable relative inhibition of purine synthesis in both groups. In three of the four normal producers the values obtained during azathioprine treatment were 20 
TABLE II

Effect of azathioprine on the incorporation of isotopic glycine into urinary uric acid

Cumulative excretion of isotope into urinary uric acid in 7 days (expressed as \% of administered dose).

\begin{tabular}{lrrr}
\hline \multicolumn{1}{c}{ Subject } & Control & $\begin{array}{c}\text { Azathio- } \\
\text { prine }\end{array}$ & $\begin{array}{c}\text { \% of } \\
\text { Control }\end{array}$ \\
\hline Primary gout, normal production & & & \\
J. F. & 0.35 & 0.07 & 20 \\
R. L. & 0.08 & 0.03 & 27 \\
E. H. & 0.14 & 0.05 & 35 \\
R. McJ. & 0.25 & 0.26 & 104 \\
Primary gout, overproduction & & & \\
T. B. & & & \\
B. P. & 1.11 & 0.28 & 25 \\
& 1.24 & 0.22 & 18 \\
Lesch-Nyhan syndrome & & & \\
D. F. & & & \\
F. H. & 2.49 & 2.70 & 108 \\
& 3.16 & 3.15 & 100 \\
\hline
\end{tabular}

TABLE III

Per cent of adm inistered azathioprine- $8-{ }^{14} \mathrm{C}$ converted to urinary uric acid

\begin{tabular}{lrccccccc}
\hline & \multicolumn{7}{c}{ Day } & \\
\cline { 2 - 8 } Subject & \multicolumn{1}{c}{1} & 2 & 3 & 4 & 5 & 6 & 7 & $\begin{array}{c}\text { Total } \\
\text { in 7 } \\
\text { days }\end{array}$ \\
\hline R. L. & 13.7 & 1.1 & 0.6 & 0.5 & 0.6 & 0.5 & 0.3 & 17.2 \\
R. McJ. & 20.5 & 0.9 & 1.0 & 0.9 & 0.8 & 0.7 & 0.6 & 25.5 \\
B. P. & 5.2 & 1.9 & 1.4 & 1.2 & 1.0 & 0.8 & 0.7 & 12.0
\end{tabular}

$35 \%$ of control values and in the overproducers $18-25 \%$ of control values. Again, purine synthesis of patient R. McJ., who was a normal producer of uric acid, was obviously resistant to the effects of azathioprine, since the cumulative incorporation of glycine- $1-{ }^{14} \mathrm{C}$ into uric acid during azathioprine treatment was $104 \%$ of the control value obtained without azathioprine. This finding is in agreement with the failure of azathioprine to diminish the excretion of uric acid in this patient ( Table I).

In contrast to the results obtained in five of the six gouty patients, both patients with the LeschNyhan syndrome showed no effect of azathioprine on the incorporation of glycine- $1-{ }^{14} \mathrm{C}$ into urinary uric acid (Table II). The maximum specific activity of uric acid in the control studies was achived in both patients F. H. and D. F. during the 6-12 $\mathrm{hr}$ period after glycine administration with values of 23,500 and $20,300 \mathrm{dpm} / \mathrm{mmole}$, respectively. Likewise, the pattern of decline in specific activity with time and the failure of azathioprine to substantially change this pattern was similar in both patients. The results obtained with patient D. F. are shown in Fig. 3. The percentage of glycine- $1-{ }^{14} \mathrm{C}$ recovered in urinary uric acid over a 7 day period was substantially greater than

TABLE IV

Effect of azathioprine treatment on urate pool size and turnover

\begin{tabular}{|c|c|c|c|c|c|c|}
\hline \multirow[b]{2}{*}{ Subject } & \multicolumn{2}{|c|}{$\begin{array}{l}\text { Miscible urate } \\
\text { pool size }\end{array}$} & \multicolumn{2}{|c|}{ Turnover rate } & \multicolumn{2}{|c|}{ Turnover } \\
\hline & Control & $\overline{\text { Aza }}$ & $\overline{\text { Control }}$ & $\overline{\text { Aza }}$ & Control & $\overline{\text { Aza }}$ \\
\hline Normal males & \multicolumn{2}{|c|}{$m g$} & \multicolumn{2}{|c|}{ pools $/ 24 \mathrm{hr}$} & \multicolumn{2}{|c|}{$m g / 24 h r$} \\
\hline Mean of 7 subjects studied (4) & \multicolumn{2}{|l|}{1071} & \multicolumn{2}{|l|}{0.58} & 622 & - \\
\hline \multicolumn{7}{|l|}{ Gout, normal production } \\
\hline $\begin{array}{l}\text { J. F. } \\
\text { R. L.* } \\
\text { E. H.* } \\
\text { R. McJ. }\end{array}$ & $\begin{array}{l}1720 \\
1670 \\
1490 \\
1510\end{array}$ & $\begin{array}{l}1660 \\
1210 \\
1040 \\
2080\end{array}$ & $\begin{array}{l}0.25 \\
0.46 \\
0.44 \\
0.44\end{array}$ & $\begin{array}{l}0.28 \\
0.44 \\
0.41 \\
0.39\end{array}$ & $\begin{array}{l}430 \\
770 \\
660 \\
660\end{array}$ & $\begin{array}{l}460 \\
530 \\
420 \\
820\end{array}$ \\
\hline \multicolumn{7}{|l|}{ Gout, overproduction } \\
\hline $\begin{array}{l}\text { B. P. } \\
\text { T. B. }\end{array}$ & $\begin{array}{l}3930 \\
2130\end{array}$ & $\begin{array}{l}2610 \\
2060\end{array}$ & $\begin{array}{l}0.60 \\
0.70\end{array}$ & $\begin{array}{l}0.49 \\
0.59\end{array}$ & $\begin{array}{l}2370 \\
1490\end{array}$ & $\begin{array}{l}1280 \\
1210\end{array}$ \\
\hline \multicolumn{7}{|l|}{ Lesch-Nyhan syndrome } \\
\hline $\begin{array}{l}\text { D. F. } \\
\text { F. H. }\end{array}$ & $\begin{array}{l}1130 \\
1690\end{array}$ & $\begin{array}{l}1170 \\
1400\end{array}$ & $\begin{array}{l}1.02 \\
0.98\end{array}$ & $\begin{array}{l}1.10 \\
1.02\end{array}$ & $\begin{array}{l}1150 \\
1650\end{array}$ & $\begin{array}{l}1290 \\
1430\end{array}$ \\
\hline
\end{tabular}

Aza, azathioprine.

* Patients receiving uric acid-8-14 $\mathrm{C}$. 
TABLE V

Effect of azathioprine on plasma and urinary oxypurines*

\begin{tabular}{|c|c|c|c|c|c|}
\hline \multirow[b]{2}{*}{ Subject } & \multicolumn{2}{|c|}{ Plasma oxypurines } & & \multicolumn{2}{|c|}{ Urinary oxypurines } \\
\hline & Control & Azathioprine & & Control & Azathioprine \\
\hline Normal range & $\begin{array}{c}\mu m / 100 m l \\
0.27-2.07(13) \ddagger\end{array}$ & $\ddagger^{\mu m / 100 m l}$ & $\cdot$ & $\begin{array}{c}\text { mmole/24 hr } \\
<0.16(5) \ddagger\end{array}$ & mmole $/ 24 \mathrm{hr}$ \\
\hline \multicolumn{6}{|c|}{ Primary gout, normal production } \\
\hline $\begin{array}{l}\text { J. F. } \\
\text { R. L. } \\
\text { E. H. } \\
\text { R. McJ. }\end{array}$ & $\begin{array}{l}0.32 \\
0.32 \\
0.30 \\
0.84\end{array}$ & $\begin{array}{l}0.36 \\
0.15 \\
0.29 \\
0.41\end{array}$ & & $\begin{array}{r}<0.01 \\
0.02 \\
0.14 \\
<0.01\end{array}$ & $\begin{array}{r}<0.01 \\
0.02 \\
0.02 \\
<0.01\end{array}$ \\
\hline \multicolumn{6}{|c|}{ Primary gout, overproduction } \\
\hline $\begin{array}{l}\text { T. B. } \\
\text { B. P. }\end{array}$ & $\underline{0.66}$ & $\begin{array}{l}0.23 \\
0.09\end{array}$ & & $\begin{array}{r}<0.01 \\
0.04\end{array}$ & $\begin{array}{l}0.05 \\
0.04\end{array}$ \\
\hline \multicolumn{6}{|c|}{ Lesch-Nyhan syndrome } \\
\hline $\begin{array}{l}\text { D. F. } \\
\text { F. H. }\end{array}$ & $\begin{array}{l}0.66 \\
1.61\end{array}$ & $\overline{0.79}$ & & $\begin{array}{l}0.22 \\
0.06\end{array}$ & $\begin{array}{l}0.19 \\
0.11\end{array}$ \\
\hline
\end{tabular}

* Oxypurines refer to the sum of xanthine and hypoxanthine.

$\ddagger$ Number of subjects.

that found in any of the gout patients. The values of 2.49 and $3.16 \%$ in patients D. F. and F. H. obtained during control studies were not significantly altered during azathioprine administration.

The conversion of azathioprine to urinary uric acid over a 7 day period after the administration of a single dose of azathioprine-8- ${ }^{14} \mathrm{C}$ is illustrated in Table III. Patient B. P. who produced excessive quantities of uric acid had a lower peak on the 1st day but somewhat higher values for the remainder of the study period when compared to patient $\mathrm{R}$. $\mathrm{L}$. who produced uric acid in a normal manner. The greatest conversion of azathioprine to uric acid was observed in patient R. McJ. who was resistant to the effects of this drug on purine synthesis despite his normal uric acid production.

Table IV demonstrates the well-known findings that the average gouty patient has an expanded urate pool size and that overproduction of uric acid in gouty patients is reflected in a significantly greater daily turnover of uric acid. In addition, the two patients with the Lesch-Nyhan syndrome also had an expanded pool size with a very high turnover rate, as noted previously (8). Calculated on a weight basis, the daily turnover in patients D. F. and F. H. was six to seven times that noted in gouty overproducers of uric acid. Azathioprine treatment produced variable effects on urate pool size and turnover.
Table $\mathrm{V}$ shows that azathioprine treatment resulted in no increase in the urinary or plasma oxypurines to account for the decrease in uric acid formation or excretion observed in some of the patients. In fact, a slight decrease in these values during azathioprine administration was observed in some patients.

The administration of azathioprine as described above resulted in no significant alterations of hematocrit, hemoglobin concentration, white blood cell count, platelet count, serum protein electrophoretic pattern, liver function tests, or renal function tests. There did appear to be a gradual reduction of reticulocytes during the period of drug administration in every case. Patients B. P. and J. F. who received the agent for a longer period of time did note some degree of nausea and anorexia, but in neither case was this severe enough for the patient to request termination of the study. No complications resulting from the presumed transient immuno-deficient state were observed.

\section{Discussion}

The findings reported by Lesch and Nyhan (11, 21) that three children with the clinical syndrome characterized by hyperuricemia, self-mutilation, and choreoathetosis showed overproduction of uric acid, overincorporation of isotopic glycine into urinary uric acid, and an expanded urate pool 
size with an increased urate turnover rate, have been supported in the present study of two additional patients. The rate of purine synthesis de novo estimated by determining the incorporation of an isotopic purine precursor, glycine- $1-{ }^{14} \mathrm{C}$, into urinary uric acid was approximately 15 times greater in these two patients than in seven normal adults. The values obtained by Lesch and Nyhan $(11,21)$ were over 200 times greater than the values they found in three control children of similar age who were mentally retarded. This discrepancy is due to differences in the control groups, since the isotope recovery values of 2.49 and $3.16 \%$ (Table II) obtained in patients D. F. and $\mathrm{F} . \mathrm{H}$. are quite comparable to the values ranging from 2.0 to $2.4 \%$ reported by Lesch and $\mathrm{Ny}$ han in three affected children. The extent to which the disparity in the control values can be attributed to the differences in the route of isotope administration, position of the ${ }^{14} \mathrm{C}$ label in the glycine molecule, or types of control subjects studied is difficult to assess.

In our study azathioprine administration suppressed purine biosynthesis de novo in two gouty patients who had overproduction of uric acid as reflected by the reduction in basal uric acid excretion and diminished incorporation of isotopic glycine into urinary uric acid. These results are in agreement with those reported by Sorensen (9, 10). However, our results differed from Sorensen's in that three of our four gouty subjects with normal uric acid production also showed an inhibition of purine synthesis de novo with azathioprine administration. The administration of azathioprine to two patients with the complete syndrome of hyperuricemia, mental retardation, spasticity, self-mutilation, and choreoathetosis, and to one patient with otherwise typical primary gout led to no detectable change in purine synthesis as measured by both balance and isotopic techniques. Sorensen also noted a similar resistance to the effects of this drug in a child who had excessive uric acid production but little or no neurological findings (22).

The uric acid formed from degradation of azathioprine constitutes a significant portion of the $24 \mathrm{hr}$ excretion in gouty patients who produce normal quantities of uric acid and, therefore, tends to mask the decrease in purine synthesis produced by azathioprine (Table III). This considera- tion may well account for the reported failure of azathioprine to inhibit purine synthesis as revealed in daily uric acid excretion in two normal subjects and one gout patient whose uric acid production was in the normal range $(9,10)$. The increase in total uric acid excretion (uncorrected) which occurred in patient R. McJ. during azathioprine treatment (Table I) without any change in glycine incorporation into urinary uric acid is readily explained by the conversion of greater than $25 \%$ of the administered azathioprine to uric acid. The extent to which an accelerated degradation of azathioprine may contribute to the increase in urinary uric acid observed in patients D. F. and F. H. remains to be determined. This conversion also complicates the interpretation of the effects of azathioprine on urate pool size and turnover. These difficulties in interpretation are compounded by the lack of constant equilibrium conditions throughout the study, as well as possible additional pharmacological actions of azathioprine.

The purine analogue 6-mercaptopurine and some of its substituted thioether derivatives, such as azathioprine, are potent inhibitors of purine synthesis in bacterial cells, in mammalian tumor cells, and in human fibroblasts $(23-26) .^{3}$ The ribonucleotide of 6-mercaptopurine is a very effective inhibitor of phosphoribosylpyrophosphate amidotransferase (27). However, the precise mechanism of inhibition of uric acid synthesis produced by these agents is not fully established. Enzymes involved in purine metabolism that have been shown in various systems to be inhibited by 6 -mercaptopurine include: phosphoribosylpyrophosphate amidotransferase $(27,28)$; adenylosuccinic acid synthetase $(29,30)$; adenylosuccinase $(31,32)$; hypoxanthine-guanine phosphoribosyltransferase (33) ; inosine phosphorylase (34) ; xanthine oxidase (35); glycinamide ribonucleotide transformylase (36) ; 5-amino-4-imidazolecarboxamide ribonucleotide transformylase (36); and inosinic acid dehydrogenase $(29,30,37,38)$. These potential sites of inhibition are indicated in Fig. 4. Inhibition of adenylic acid synthetase, adenylosuccinase, and/or inosinic acid dehydrogenase by azathioprine would produce an alteration in ino-

\footnotetext{
${ }^{3}$ Rosenbloom, F. M., J. F. Henderson, W. N. Kelley, and J. E. Seegmiller. Inhibition of purine synthesis by azathioprine in fibroblasts. In preparation.
} 


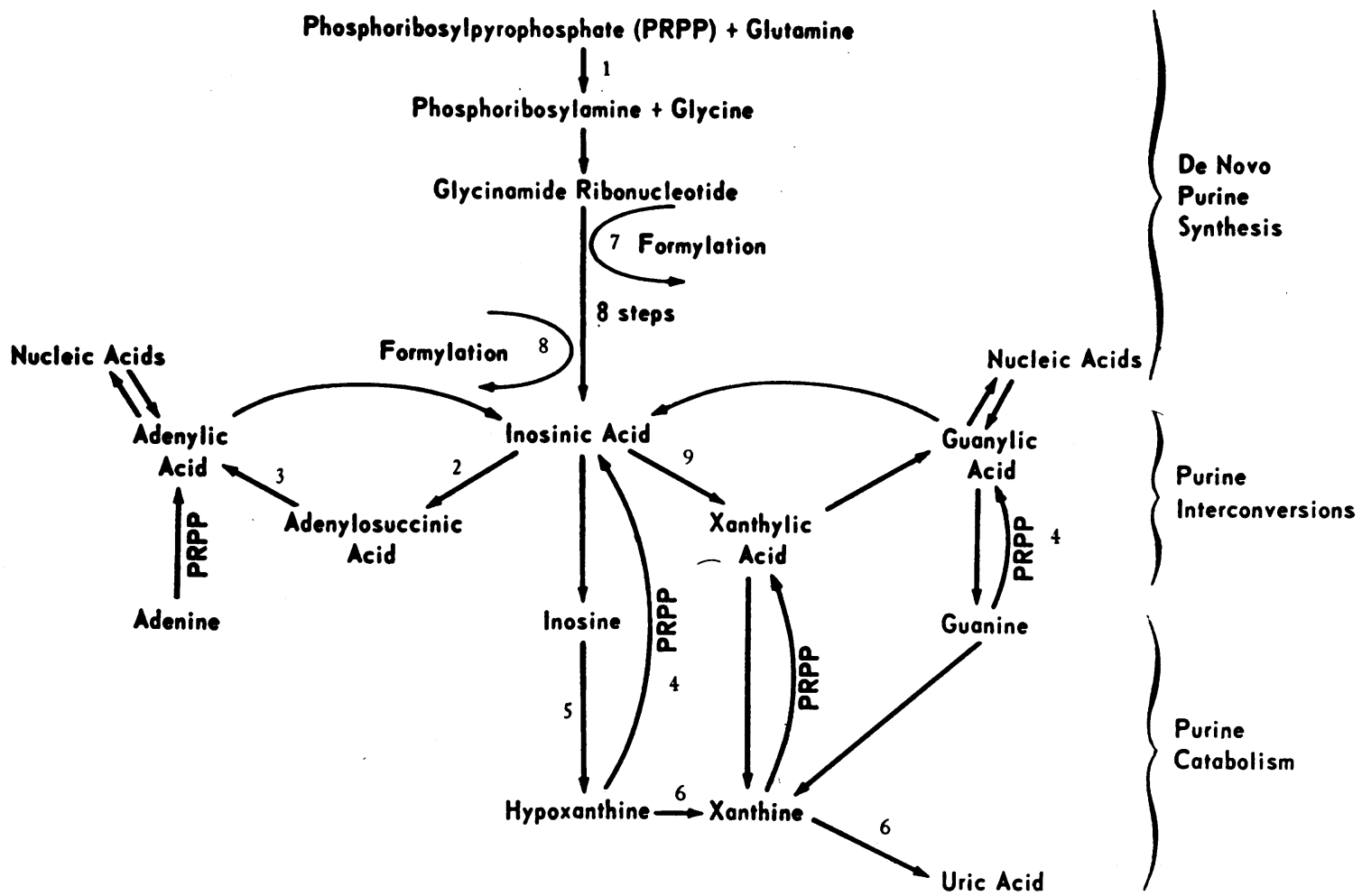

Fig. 4. Pathways of pUrine metabolism in man. Enzymes demonstrated by others to be inhibited by 6-mercaptopurine are: 1, phosphoribosylpyrophosphate amidotransferase $(27,28) ; 2$, adenylosuccinic acid synthetase $(29,30) ; 3$, adenylosuccinase $(31,32) ; 4$, hypoxanthine-guanine phosphoribosyltransferase $(33)$; 5 , inosine phosphorylase $(34) ; 6$, xanthine oxidase $(35) ; 7$, glycinamide ribonucleotide transformylase $(36) ; 8$, 5-amino-4-imidazolecarboxamide ribotide transformylase $(36)$; and 9 , inosinic acid dehydrogenase $(29,30,37,38)$.

sinic acid metabolism which would not be expected to produce the decrease in uric acid synthesis observed with the administration of this drug. The finding that urinary and plasma oxypurines were not increased during azathioprine administration is evidence that inhibition of xanthine oxidase was not responsible for the decrease in uric acid formation. The fact that oxypurine content of plasma and urine did not decrease markedly suggests that inosine phosphorylase was not inhibited.

From our present studies we cannot exclude the possibility that the suppressive effect noted in five of six gouty patients was mediated by inhibition of the formylation steps in the de novo pathway. The available evidence in other systems, however, would suggest that the rate-limiting step catalyzed by phosphoribosylpyrophosphate amidotransferase is at least 16 times more sensitive to inhibition by purine nucleotides than the remaining enzymes required for the formation of inosinic acid (39).
These findings thus suggest that excessive uric acid formation in the gouty patients studied does not result-from an alteration in the sensitivity of the phosphoribosylpyrophosphate amidotransferase to feedback inhibition at the allosteric sites on the enzyme responsible for its inhibition by this group of compounds. A similar conclusion has been reached in recent studies in which exogenous adenine $-{ }^{13} \mathrm{C}$ has been shown to inhibit the de novo purine pathway equally in both varieties of gout. ${ }^{4}$ The remaining possibilities that excessive purine synthesis in gouty patients may be the result of a diminished concentration of purine ribonucleotides that function as feedback inhibitors or an increase in concentration of substrates for the rate-limiting enzyme cannot be resolved in our study.

The lack of inhibition of purine synthesis de

${ }^{4}$ Seegmiller, J. E., J. R. Klinenberg, and R. W. E. Watts. The incorporation of adenine-8- $\mathrm{C}^{13}$ into urinary uric acid in normal and gouty subjects. In preparation. 
novo in response to azathioprine observed in the two patients with the Lesch-Nyhan syndrome, D. F. and F. H., implies that they differ biochemically from the gouty patients studied. Although the exact mechanism of this resistance cannot be deduced from the data presented, the possibility that it may be directly related to an aberrant control mechanism in these patients is apparent. The demonstration of a deficiency in the enzyme hypoxanthine-guanine phosphoribosyltransferase (PRTase) in these patients provides a biochemical explanation for their failure to respond to azathioprine (40). The missing enzyme is required for conversion of 6-mercaptopurine presumably derived from azathioprine to the ribonucleotide form necessary for its function as a feedback inhibitor of purine synthesis. A partial deficiency of this enzyme $(0.5-10 \%$ of normal) has recently been described in five gouty subjects who produce excessive quantities of uric acid (41). As would be expected azathioprine had no effect on purine synthesis in two of these patients.

An additional primary defect at the level of the rate-limiting enzyme in purine biosynthesis de novo, phosphoribosylpyrophosphate amidotransferase, is probably not the cause of the excessive purine synthesis observed in the patients with the Lesch-Nyhan syndrome, since the initial steps of purine synthesis studied in vitro with fibroblasts obtained from these patients can be inhibited by another purine analogue, 6-methylmercaptopurine riboside. $^{3}$

Patient R. McJ. noted to be resistant to the effects of azathioprine on purine synthesis appeared otherwise at the time of these studies to have typical gout with production of uric acid in the normal range. Erythrocyte PRTase activity was normal, indicating that this resistance to azathioprine occurred by a mechanism different from that demonstrated in patients with the Lesch-Nyhan syndrome. Clinically, he in no way resembled these patients and careful review of the family with the patient failed to reveal features characteristic of this syndrome in other family members. Preliminary studies with azathioprine- $8-{ }^{14} \mathrm{C}$ suggest that an increased catabolism of this purine analogue may contribute to the resistance observed ( $\mathrm{Ta}$ ble III). Since completion of these studies this patient has developed overt polycythemia vera providing a clinical difference from the other gouty patients.

Azathioprine has proven to be a valuable investigative tool with which to evaluate the control of human purine metabolism in vivo. The variation observed in response to this drug has provided new insight into the biochemical aberrations present in some of these patients, as well as further evidence for the heterogeneity of such disorders.

\section{References}

1. Benedict, J. D., M. Roche, T. F. Yü, E. J. Bien, A. B. Gutman, and DeW. Stetten, Jr. 1952. Incorporation of glycine nitrogen into uric acid in normal and gouty man. Metab. Clin. Exptl. 1:3.

2. Gutman, A. B., T. F. Yü, H. Black, R. S. Yalow, and S. A. Berson. 1958. Incorporation of glycine$1-\mathrm{C}^{14}$, glycine-2- $\mathrm{C}^{14}$ and glycine- $\mathrm{N}^{15}$ into uric acid in normal and gouty subjects. Am. J. Med. 25: 917.

3. Wyngaarden, J. B. 1957. Overproduction of uric acid as the cause of hyperuricemia in primary gout. J. Clin. Invest. 36: 1508.

3. Seegmiller, J. E., A. I. Grayzel, L. Laster, and L. Liddle. 1961. Uric acid production in gout. $J$. Clin. Invest. 40: 1304.

5. Nierlich, D. P., and B. Magasanik. 1965. Regulation of purine ribonucleotide synthesis by end product inhibition. J. Biol. Chem. 240: 358.

6. Caskey, C. T., D. M. Ashton, and J. B. Wyngaarden. 1964. The enzymology of feedback inhibition of glutamine phosphoribosylpyrophosphate amidotransferase by purine ribonucleotides. J. Biol. Chem. 239: 2570.

7. Henderson, J. F. 1962. Feedback inhibition of purine biosynthesis in ascites tumor cells. J. Biol. Chem. 237: 2631.

8. Wyngaarden, J. B. 1966. Gout. In The Metabolic Basis of Inherited Disease. J. B. Stanbury, J. B. Wyngaarden, and D. S. Fredrickson, editors. McGraw-Hill Book Co., Inc., N. Y. 2nd edition. 667.

9. Sorensen, L. B. 1966. Suppression of the shunt pathway in primary gout by azathioprine. Proc. Natl. Acad. Sci. 55: 571.

10. Sorensen, L. B. 1966. Suppression of the shunt pathway in primary gout by azathioprine. J. Clin. Invest. 45: 1075. (Abstr.)

11. Lesch, M., and W. L. Nyhan. 1964. A familial disorder of uric acid metabolism and central nervous system function. Am. J. Med. 36: 561.

12. Schoenheimer, R., and S. Ratner. 1939. Studies in protein metabolism. III. Synthesis of amino acids containing isotopic nitrogen. J. Biol. Chem. 127: 301.

13. Müller, A. F., and W. Bauer. 1953. Uric acid production in normal and gouty subjects determined 
by $\mathrm{N}^{15}$-labeled glycine. Proc. Soc. Exptl. Biol. Med. 82: 47.

14. Grayzel, A. I., J. E. Seegmiller, and E. Love. 1960. Suppression of uric acid synthesis in the gouty human by the use of 6-diazo-5-oxo-L-norleucine. $J$. Clin. Invest. 39: 447.

15. Benedict, J. D., P. H. Forsham, and DeW. Stetten, Jr. 1949. The metabolism of uric acid in the normal and gouty human studied with the aid of isotopic uric acid. J. Biol. Chem. 181: 183.

16. Liddle, L., J. E. Seegmiller, and L. Laster. 1959. The enzymatic spectrophotometric method for determination of uric acid. J. Lab. Clin. Med. 54: 903.

17. Klinenberg, J. R., S. Goldfinger, K. H. Bradley, and J. E. Seegmiller. An enzymatic spectrophotometric method for the determination of xanthine and hypoxanthine. Clin. Chem. In press.

18. Taussky, H. H. 1954. A microcolorimetric determination of creatine in urine by the Jaffé reaction. J. Biol. Chem. 208: 853 .

19. Hoefnagel, D., E. D. Andrew, N. G. Mireault, and W. O. Berndt. 1965. Hereditary choreoathetosis, self-mutilation and hyperuricemia in young males. New Engl. J. Med. 273: 130.

20. Hamilton, L., and G. B. Elion. 1954. The fate of 6-mercaptopurine in man. Ann. N. Y. Acad. Sci. 60: 304 .

21. Nyhan, W. L., W. J. Oliver, and M. Lesch. 1965. A familial disorder of uric acid metabolism and central nervous system function. II. J. Pediat. 67: 257 .

22. Sorensen, L., and P. J. Benke. 1967. Biochemical evidence for a distinct type of primary gout. Nature. 213: 1122.

23. Skipper, H. E. 1954. On the mechanism of action of 6-mercaptopurine. Ann. N. Y. Acad. Sci. 60: 315.

24. Brockman, R. W. 1965. Resistance to purine antagonists in experimental leukemia systems. Cancer Res. 25: 1596.

25. Henderson, J. F. 1965. Effects of anticancer drugs on biochemical control mechanisms. Progr. Exptl. Tumor Res. 6: 84.

26. Elion, G. B., and G. H. Hitchings. 1965. Metabolic basis for the actions of analogs of purines and pyrimidines. Advan. Chemotherapy. 2: 91.

27. McCollister, R. J., W. R. Gilbert, D. M. Ashton, and J. B. Wyngaarden. 1964. Pseudofeedback inhibition of purine synthesis by 6-mercaptopurine ribonucleotide and other purine analogs. J. Biol. Chem. 239: 1560 .
28. Bennett, L. L., L. Simpson, J. Golden, and T. L. Barker. 1963. The primary site of inhibition of 6-mercaptopurine on the purine biosynthetic pathway in some tumors in rivo. Cancer Res. 23: 1574.

29. Salser, J. S., D. J. Hutchison, and M. E. Balis. 1960. Studies on the mechanism of action of 6-mercaptopurine in cell free preparations. J. Biol. Chem. 235: 429.

30. Salser, J. S., and M. E. Balis. 1965. The mechanism of action of 6-mercaptopurine. I. Biochemical effects. Cancer Res. 25: 539.

31. Hampton, A. 1962. Studies of the action of adenylosuccinase with 6-thio analogues of adenylosuccinic acid. J. Biol. Chem. 237: 529.

32. Bridger, W. A., and L. H. Cohen. 1963. The mechanism of inhibition of adenylosuccinate lyase by 6mercaptopurine nucleotide (Thioinosinate). Biochim. Biophys. Acta. 73: 514.

33. Atkinson, M. R., and A. W. Murray. 1965. Inhibition of purine phosphoribosyltransferases of Ehrlich ascites tumor cells by 6-mercaptopurine. Biochem. J. $94: 64$.

34. Tomisek, A. J., A. P. U. Hoskins, and M. R. Reid. 1965. Chromatographic studies of purine metabolism. VI. Inhibition of inosine phosphorylase by 6-mercaptopurine. Cancer Res. 25: 1925.

35. Ultmann, J. E., and P. Feigelson. 1958. The effects of 8-azaguanine and 6-mercaptopurine on purine catabolism in the rat. Cancer Res. 18: 1319.

36. Wilmanns, W. 1962. Zum Wirkungsmechanisms von 6-mercaptopurin. Klin. Wochschr. 40: 1170.

37. Atkinson, M. R., R. K. Morton, and A. W. Murray. 1963. Inhibition of inosine-5'-phosphate dehydrogenase from Ehrlich ascites tumor cells by 6thioinosine-5'-phosphate. Biochem. J. 89: 167.

38. Hampton, A. 1963. Reactions of ribonucleotide derivatives of purine analogs at the catalytic site of inosine-5'-phosphate dehydrogenase. J. Biol. Chem. 238: 3068.

39. Wyngaarden, J. B., H. R. Silberman, and J. H. Sadler. 1958. Feedback mechanisms influencing purine ribotide synthesis. Ann. N. Y. Acad. Sci. 75: 45.

40. Seegmiller, J. E., F. M. Rosenbloom, and W. N. Kelley. 1967. An enzyme defect associated with a sex-linked human neurological disorder and excessive purine synthesis. Science. 155: 1682.

41. Kelley, W. N., F. M. Rosenbloom, J. F. Henderson, and J. E. Seegmiller. A specific enzyme deficit in gout associated with overproduction of uric acid. Proc. Natl. Acad. Sci. 57: 1735. 